to make public that they will not sponsor research that might threaten the sales of their products, but they do control the kind of research done. The drink trade will happily sponsor pharmacological research on rats' livers that might just come up with a drug that will prevent the physical complications of alcohol abuse no matter how much a person drinks, but it will be much less keen to back research that provides conclusive evidence that alcohol advertising increases overall consumption. Indeed, it will almost certainly refuse. Then there is the worry that in some unseen subtle way the knowledge of who is paying the piper will influence the results. The randomised double blind trial has been called the greatest medical discovery of the century because it so effectively reduces the bias that tends to creep in everywhere, and yet here researchers are being forced to increase the sources of bias in their research by taking money from groups that would much prefer the results to point one way rather than another.

The case against taking money from the drink trade is said to be more complicated because of the dubious evidence that "a little of what you fancy does you good." Most people in Britain drink, and only a minority, the argument goes, are harmed in any way by their drinking: the drink trade is thus selling a product that may bring benefits, making it quite different from the tobacco industry, which is selling a product that is wholly harmful. The argument is fallacious, however, not only because the evidence is unconvincing that a little alcohol is beneficial and because most of the people in Britain who drink may in some way harm themselves through their drinking (even if with nothing more than hangovers), but also because the drink trade is committed to selling as much alcohol as it can-and the evidence is incontrovertible that the more alcohol a society consumes the more damage it will suffer.

The drink trade does not like its customers dying of cirrhosis or ruining their marriages and would like to see a world where everybody drank in moderation and nobody to excess. But such a world is not possible, and if Britain wants drastically to reduce its alcohol problems then it must halve its consumption. And doctors or health educators who argue such will find themselves just as much in conflict with the drink trade as those who argue for a tobacco free society are with the tobacco industry. The same arguments thus apply for not taking money from the drink trade.

It would be extreme to suggest that the same arguments apply to taking money from the food or drug industries, but researchers should surely endeavour to ensure that not all of their money comes from these sources. The cosy relationship between doctors and the drug industry has come in for increasing public criticism, and the Royal College of Physicians has become worried enough to set up a working party to investigate the relationship. It will surely suggest that doctors try to disentangle themselves more from drug companies - as has happened in Sweden. The worry is not so much that doctors are corrupted by the relationship -although such a worry is always present-but rather that doctors may be too strongly influenced by drug companies in their prescribing. Furthermore, the closeness of the relationship between the industry and doctors may have led doctors into being too quick to look for pharmacological solutions to medical and even social problems. Perhaps the excessive tranquillising of the British population with its attendant addiction and damage might have been avoided. Most doctors are not conducting any research, and their financial dealings with the drug industry are restricted to sponsored meetings and small gifts, but an increasing number of doctors are wary even of these minor inducements.

The $B M \mathcal{F}$ is, of course, partly dependent itself on the revenue that it receives from drug advertising, but we try not to be editorially influenced by this money (while recognising that it may have some subliminal effects). Advertisements are taken from many different sources; all are reviewed before publication; space is given when necessary to criticisms of their content and style; and there are systems for complaining about them. Furthermore, we have published many "first" reports of adverse reactions to drugs and will continue to do so, despite offended companies removing their advertising from the journal as they have done before. Interestingly, too, when international medical editors were asked at a meeting whether, if it was financially feasible, they would like to publish journals without advertisements all but one said that they would.

Finally, the arguments against taking money from these various industries operate even more strongly when it comes to writing reports. The public is rightly suspicious when a report sponsored by the Frog Marketing Board suggests that increased frog consumption is associated with lower mortality from cancer, and when a series of judgments must be made about conflicting evidence full independence is indispensable. The council for the BMA was thus right to reject taking money from the Meat Livestock Commission to write a report on diet and health, although the association did take money from a group of companies in the drinks industry to produce what proved to be an unacceptable report on alcohol and the young.

The BMA will find the money itself to write the report on diet. We believe that the government should find the money to back the research that needs to be done into helping those damaged by tobacco, alcohol, and other products. Researchers would not then have to take the tainted money of the Health Promotion Research Trust and the drink trade. One way that the government could raise the money would be by increasing tax on cigarettes and alcohol. Although this might seem like yet another way of "supping with the devil," it is not because the evidence is so strong that consumption of both products would fall as a result. If $1 \mathrm{p}$ were added to each packet of cigarettes sold then about $£ 50 \mathrm{~m}$ could be raised for research- $40 \%$ of the current Medical Research Council budget.

\section{A false phoenix}

Twenty years ago René Dubos drew attention to the revival of what was then called fringe medicine and argued that this was evidence of "the failure of the present biomedical science to satisfy large human needs." The revival has been sustained to the point that alternative medicine is now widely perceived as a serious competitor with orthodox medicine. The medical establishment has reacted defensively, recognising the growing interest among both patients and doctors in homoeopathy, acupuncture, herbalism, hypnosis, and the scores of other approaches to the relief of physical and mental disorders; the BMA's board of science is concluding an inquiry into alternative medicine, the College of Health is beginning one, and the man (or patient) in the street is apparently convinced that "there is something in it." 
Yet some doctors who see the results of some patients being treated by alternative medicine are becoming disturbed. Their doubts have been aired at two recent conferences on the treatment of patients with cancer. These patients usually come to terms bravely with their initial diagnosis-but in the hope that their primary treatment will eliminate the disease. When they relapse that hope is destroyed. Many despair; and in their despair some turn to alternative therapists. The dangers of these therapies were vividly described by Professor Kenneth Calman. Dietary treatment, for example, often required patients to follow an unpalatable, expensive regimen-and if (as would be natural) they sometimes ate forbidden foods or omitted others they became guilty and miserable. Psychological techniques such as visualisation (in which the patient directs his or her thoughts against the tumour, visualising its destruction) were even more likely to engender guilt when they failed. Alternative drugs such as Laetrile and Iscador could be toxic. And even cancer support groups could cause great distress to patients by clumsy, inappropriate attempts at group psychotherapy. With each of these therapies patients were led to believe that progression of their disease implied that they had not worked hard enough at the method; the initial optimism promoted by the therapistthat a miracle was possible-was replaced at the end by hopelessness made worse by guilt.

Another target for medical anger are the frauds and quacks who are profiting from the amount of interest in alternative medicine. Many people seem to believe that treatment supplied free in a grubby outpatient department cannot be as good as something they pay for in an expensive clinic. Advertisements in "health" magazines, fashionable shops in city centres, and an endless flow of plausible books give the impression that hair analysis for the detection of trace mineral deficiencies or iridology (diagnosis by examination of the iris) are as scientifically respectable as manipulation of the spine for backache. Fringe medicine (as I think we should still describe the diagnostic and therapeutic techniques which make no scientific sense whatever) has become a getrich-quick industry for the unscrupulous. Established alternative therapists such as homoeopathic physicians or osteopaths should surely be just as concerned as orthodox doctors at this cynical exploitation of the sick. Selling hope by making false claims of certain cure has been the mark of the charlatan down the ages.

Medical critics of alternative medicine believe that its practitioners should answer some specific questions. First and crucially, does the system offer an alternative treatment while accepting orthodox medical explanations for the causes of migraine, or asthma, or cancer? Or does it have a quite distinct philosophy of disease, such as the need for a balance between yin and yang in Chinese medicine, the malalignments of the spine thought responsible for disease in osteopathy, or the conviction of clinical ecologists that allergies to food, food additives, and chemicals explain much chronic disease?

If the alternative system recognises conventional pathogenesis and diagnosis are its practitioners adequately trained in making those diagnoses? And does the system claim to have remedies for the whole spectrum of disease? The established systems such as homoeopathy make no claim to be able to cure tuberculosis, hypothyroidism, basal cell carcinoma, or benign prostatic hypertrophy with the certainty offered by conventional medicine. By contrast, some alternative therapists are so confident of their abilities that we believe that patients with curable disorders of those kinds may be denied the specific treatment they need.

For even if an alternative system is self contained and is based on a variant theory of disease then as physicians we have a duty to ask how patients with serious, treatable disorders are recognised and treated. Next, we may reasonably ask what sort of audit of their outcome has been attempted. No alternative system of medicine has equivalents to morbid anatomy and histopathology. Without some means of validating diagnosis how can anyone claim to validate treatment?

The response of some alternative practitioners to challenges of this kind is to assert that their methods rely on an empathic relation between practitioner and patient, making formal randomised clinical trials impossible-and some add that they are too busy to attempt any kind of evaluation. That might be acceptable so long as they restricted their therapies to patients with neurotic and personality disorders and the many chronic organic diseases (from rheumatoid arthritis to multiple sclerosis) for which orthodox medicine has only symptomatic treatments to offer. And of course it is true that the time, sympathy, and concern shown for patients of this kind by alternative practitioners is valuable; indeed their results have opened the eyes of orthodox doctors to the virtues of whole person medicine, and we have changed as a result.

Orthodox doctors have been polite and even generous in acknowledging the communication skills of many dedicated alternative practitioners, but the growth of the unscrupulous fringe has reached the point that the medical profession must now make a clear challenge. We have waited and watched for 20 years, but alternative therapists show few signs of recognising the merits of the scientific method. If any group of these therapists wants to assert its professional status (and claim payment from NHS funds) it must present evidence of some formal system of training together with some audit of competence and outcome. Therapists who reject that approach cannot expect either respect or cooperation from the medical profession.

\section{Intolerance, 1980s' style}

When Oscar Wilde was sentenced to a prison term for a homosexual offence it is said that the harlots danced for joy in the streets-while when he was travelling to Reading Gaol bystanders on a station platform spat in his face. Since then the attitudes of the public in general and of doctors in particular have changed-or have they?

For the past three years the $B M \mathcal{F}$ has been carrying a small advertisement for the Gay Medical Association. On the face of it, enmeshed among other small advertisements and discreetly worded, it would hardly have been expected to be given more than a passing glance-yet it provoked angry letters to the editor and even a debate at the Annual Representative Meeting. The tone of the letters was often intolerant, even hectoring, ending with a single demand: that the advertisement should be withdrawn and banned. Some of the statements made might challenge the concept of a liberal profession. 